\title{
COMÉRCIO JUSTO E SEGURANÇA ALIMENTAR
}

\author{
Isabel Fernandes Pinto Viegas ${ }^{1}$
}

O objetivo deste trabalho é relacionar o conceito de Segurança Alimentar em áreas rurais à certificação de Comércio Justo (Fair Trade) e verificar se o Comércio Justo é um dos caminhos para se promover a melhoria das condições de Segurança Alimentar por intermédio da maior inserção de produtores agrícolas marginalizados. A metodologia adotada foi revisão bibliográfica relacionando segurança alimentar, desenvolvimento rural, tendências do comércio internacional com suas consequências e Comércio Justo, tratando possíveis interações e limitações. As tendências recentes têm acentuado as dificuldades das populações agrícolas de países subdesenvolvidos em relação à competitividade, acesso ao mercado e aumentado sua vulnerabilidade com relação ao acesso aos recursos que poderiam garantir-lhes Segurança Alimentar. O Comércio Justo é apresentado como uma alternativa de desenvolvimento agrícola. Os preços mais altos dos seus produtos são fundamentais para garantir a sobrevivência de produtores menos eficientes e competitivos do que os padrões estabelecidos em termos globais. Implica no reconhecimento pelo consumidor de aspectos sociais, ambientais e da qualidade do produto. Ao garantir a inclusão crescente de produtores agrícolas marginalizados, o Comércio Justo poderia ser efetivo em possibilitar maiores rendimentos e um maior acesso econômico à satisfação de suas necessidades básicas, inclusive à Segurança Alimentar.

Palavras-chave: comércio justo, economia solidária, agricultura e segurança alimentar.

\section{FAIR TRADE AND FOOD SECURITY}

The aim of this paper is to relate food security in rural areas and Fair Trade certification, verifying if Fair Trade is a way to promote better conditions of food security by inserting marginalized agricultural producers in market. The methodology adopted was literature revision to relate food security, rural development, international trade tendencies and consequences and Fair Trade, showing some interactions and limitations. World tendencies have been improved agricultural population difficulties of competition and market access, and this has been improved the vulnerability of this population to food insecurity. Fair Trade is presented as a way to promote agricultural development. Higher prices of products are important to warrant that less competitive producers remain in the market. This implies in the consumer's recognition of social, environmental aspects besides, product quality. The warrant of increasing insertion of marginalized agricultural producers in market could improve income and access to better basic conditions, including food security.

Key words: fair trade, solidarity economy, agriculture, food security.

1 Pesquisadora APTA. Doutoranda do Programa de Desenvolvimento Econômico- Instituto de Economia - UNICAMP, Campinas, SP. Endereço: Rua Francisco José Machado, 316, CEP: 13420-004. Piracicaba, SP. Tel.19 81126606.E-mail: isabel_viegas@hotmail.com 


\section{Introdução}

A pobreza rural tem sido uma constante nos países latino-americanos nas últimas décadas, resultando muitas vezes em insegurança alimentar. Embora sejam fenômenos com forte correlação empírica, pobreza e insegurança alimentar não podem ser confundidas pois, ao mesmo tempo que parte da população com insegurança alimentar não corresponde aos mais pobres, parte da população mais pobre não tem problema de segurança alimentar ${ }^{[1]}$.

As áreas rurais dos países subdesenvolvidos, em geral apresentam deficiências em relação à infra-estrutura e educação, além de recursos financeiros e técnicos escassos. Os aspectos limitantes dessas áreas referem-se à falta de atividades rentáveis, às dificuldades de serem criados e mantidos sistemas de produção, à insuficiência de insumos e à dificuldade de acesso à rede de distribuição. Características comuns mais graves referemse à insuficiência de alimentos, de acesso à compra de bens de consumo básicos e aos serviços públicos, como saúde e educação. Dessa forma, a pobreza rural é um fenômeno complexo e bastante heterogêneo, sendo o desenvolvimento econômico e social desse setor fator de importância decisiva para o alcance da segurança alimentar. Melhorias nessas características devem levar à maior inserção no mercado - reduzindo as desigualdades de oportunidades e proporcionando um rendimento justo do trabalho - e ao incremento do emprego rural de melhor qualidade.

No Brasil, um dos fatores decisivos para a proliferação da pobreza rural foi a forma excludente pela qual se processou a modernização da agricultura, com o mercado se apropriando dos avanços científicos e colaborando para a concentração de capitais a montante e a jusante da produção rural. Assim, o espaço rural tornou-se uma espécie de resíduo do processo de industrialização, fundamental para a reprodução do sistema capitalista, mas intrinsecamente atrasado. A política agrícola adotada favorecia a agricultura de grande escala, levando ao esvaziamento do campo e inibição do desenvolvimento local [2]. Criou-se e moldou-se um ambiente institucional específico para atender $o$ agronegócio e ao qual a agricultura familiar foi posta à margem devido à sua lógica de produção em menor escala [3]. Nesse modelo, o desempenho é avaliado por medidas meramente econômicas, excluindo aspectos sociais e ambientais. Dessa forma, o agronegócio imprime tendências sistemáticas de redução da participação relativa da renda da produção agrícola, tendo consequências não só na esfera econômica, mas para o desenvolvimento como um todo. O Comércio Justo é apresentado como uma certificação que visa possibilitar a inserção de produtores agrícolas de países subdesenvolvidos no mercado internacional de forma mais igualitária. Isso se deve à sua interpretação multifuncional da agricultura familiar, que agrega a ela uma visão sociopolítica na qual a sua importância não se restringe ao fornecimento de produtos ao mercado mas, inclui aspectos relacionados à proteção ambiental, questões sociais, qualidade dos produtos e dinamização dos territórios rurais [4]. O objetivo deste trabalho é relacionar o conceito de Segurança Alimentar em áreas rurais à certificação de Comércio Justo (Fair Trade) e verificar se pode existir uma interação entre eles, ou seja, se o Comércio Justo é um dos caminhos para se promover a melhoria das condições de Segurança Alimentar por intermédio da maior inserção de produtores agrícolas marginalizados.

Para atender a esses objetivos, este artigo foi dividido em seções: na primeira, foi apresentado o conceito de segurança alimentar, os compromissos estabelecidos na Declaração de Roma com relação ao desenvolvimento rural, ressaltando o problema do acesso econômico aos alimentos e a relação estreita entre segurança alimentar e agricultura. $\mathrm{Na}$ segunda seção foram discutidas algumas tendências do comércio internacional e algumas consequências para os pequenos produtores agrícolas de países subdesenvolvidos. $\mathrm{Na}$ terceira seção foram apresentados os critérios do Comércio Justo e suas especificidades. Na quarta seção foi apresentada a base teórica sobre a qual convergem os conceitos de comércio justo e segurança alimentar. $\mathrm{Na}$ quinta seção, foram discutidas as possíveis contribuições do Comércio Justo para a segurança alimentar e algumas limitações.

\section{Segurança Alimentar e Agricultura}

O conceito de Segurança Alimentar teve origem após a I Guerra Mundial, quando o abastecimento de alimentos era considerado uma arma e, portanto, uma questão de soberania nacional, trazendo à tona a importância de auto-suprimento e de estoques de alimentos. Nesse contexto surgiu a Revolução Verde, sob $\mathrm{o}$ argumento de que o aumento da produtividade agrícola por meio da modernização da agricultura resolveria $\mathrm{o}$ problema da escassez de alimentos e da fome. No entanto, tais problemas não foram resolvidos mostrando que as questões ligadas ao abastecimento não eram as 
únicas pertinentes para a insegurança alimentar. Tal constatação sinalizou para um problema maior de acesso aos alimentos mesmo em circunstâncias de plena disponibilidade. Além da disponibilidade e do acesso, o conceito de segurança alimentar também envolve questões referentes à qualidade e sanidade dos alimentos, ao respeito aos hábitos e cultura alimentares e à sustentabilidade do sistema alimentar, no sentido de manutenção da capacidade futura de produção, distribuição e consumo. Tal conceito é bastante heterogêneo e multidimensional, sendo assim fonte de conflitos ${ }^{[5}$. Estabelece o acesso regular e permanente a alimentos suficientes, seguros e nutritivos que atendam às necessidades nutricionais, às preferências individuais e que respeitem a diversidade cultural, sendo ambiental, social e economicamente sustentáveis. A noção de soberania alimentar implica na liberdade de decisão de o que e como comer e produzir, não desrespeitando os aspectos culturais ${ }^{[6]}$.

De acordo com a Declaração de Roma, aprovada por chefes de Estado e do governo durante a Cúpula Mundial de Alimentação em 1996, a oferta de alimentos tem apresentado uma tendência de crescimento, reforçando que um dos principais entraves à Segurança Alimentar reside na restrição ao acesso. Dessa forma, o problema da fome e da insegurança alimentar ainda persiste e aumenta dramaticamente em algumas regiões, sendo a pobreza considerada sua maior causa. Segundo a FAO [7, a fome é tanto causa como efeito da pobreza.

O documento aponta para a necessidade de aumento da produção de alimentos dentro de padrões de consumo e produção que apresentem simultaneamente sustentabilidade econômica, social e ambiental. Nele foram estabelecidos compromissos que incluem a criação de condições políticas, econômicas e sociais para proporcionar acesso físico e econômico igualitário aos alimentos, produção com práticas sustentáveis, investimentos públicos e privados, desenvolvimento da produção, medidas para evitar catástrofes e emergências e implementação de um sistema comercial mundial justo. O conjunto desses compromissos tem a finalidade de erradicar a pobreza, as desigualdades e promover a segurança alimentar ${ }^{[8]}$.

Dentre esses compromissos pode-se destacar a ênfase no desenvolvimento agrícola como fator de combate à pobreza e garantia de Segurança Alimentar, que considera como prioritária a revitalização de áreas rurais para garantir a estabilidade social das pessoas que nelas vivem e para evitar a migração excessiva para áreas urbanas. Mesmo com o abastecimento adequado, a pobreza impede o acesso econômico a esses alimentos ${ }^{[8]}$.

A segurança alimentar é de interesse de toda a comunidade internacional devido às suas implicações em relação à estabilidade política e na promoção da paz, erradicação da pobreza, prevenção e reações a crises, proteção do meio ambiente, redução de desequilíbrios demográficos. A sustentabilidade de políticas de segurança alimentar é garantida com o envolvimento complementar do mercado, do Estado e da sociedade civil atuando na fiscalização, mobilização social, transcendendo interesses políticos [?].

\section{Tendências, mercado e desenvolvimento}

Segundo Mazoyer \& Roudart [10], a revolução agrícola somada à revolução dos transportes colocou em concorrência agriculturas de países em diferentes graus de desenvolvimento e essa concorrência deixou agricultores mais pobres de países subdesenvolvidos em condições cada vez piores. O progresso das técnicas utilizadas veio acompanhado de redução nos preços dos alimentos, deixando os produtores marginalizados abaixo do limiar de renovação, ou seja, acentuou ainda mais as desigualdades, na medida em que impediu que o progresso alcançasse os mais desfavorecidos. Mesmo com a redução dos preços, muitos pequenos agricultores de países subdesenvolvidos se mantiveram na agricultura de exportação, assim seus custos e o valor recebido pelo produto foram convergindo. No extremo, quando a produção para o autoconsumo é suprimida por uma maior produção para a exportação na tentativa de melhorar a sua renda, o agricultor passa para baixo do limiar de sobrevivência. Dessa forma, esses agricultores sobrevivem por algum tempo dos rendimentos do subconsumo, subalimentação e da descapitalização, até que se esgotem os recursos. Tal fato, normalmente, implica na tendência à migração, com repercussões para a área urbana de forma cumulativa, além de consequências sociais, ambientais e econômicas na área rural.

A agricultura brasileira, de modo geral, está plenamente inserida no comércio internacional. Esse sistema, por sua vez, tem sido injusto, com políticas discriminatórias em relação aos países subdesenvolvidos e barreiras mais restritivas para os produtos com vantagens comparativas nos países em desenvolvimento, tais como commodities agrícolas brutas e processadas e bens de consumo simples. Apesar de as negociações internacionais sinalizarem alguma preocupação em termos de desenvolvimento econômico e combate à pobreza nos países em desenvolvimento, esses compromissos não vêm sendo cumpridos ou vêm sendo 
executados muito vagarosamente, principalmente em relação à redução tarifária para produtos com grande conteúdo de mão-de-obra. Ao mesmo tempo que a liberalização pode beneficiar consumidores com preços mais baixos, do ponto de vista dos produtores agrícolas, a concorrência com produtos subsidiados pode levá-los ao desemprego e abandono da atividade. Em países em desenvolvimento, os benefícios sociais do empreendedorismo, geralmente, são maiores que as expectativas de retorno privado; portanto, para melhorar a distribuição de renda, talvez sejam necessários desvios em relação à eficiência técnica ${ }^{[1]}$.

A agricultura tende a ser mais extensiva, integrada, contratual, globalizada e dependente de serviços. A adoção de novas matrizes tecnológicas coloca-se no centro da concorrência. Essas tendências são acompanhadas da necessidade cada vez maior de informação, inclusão de etnias e gêneros na agricultura, associativismo, políticas diferenciadas, territorializadas e sustentáveis [9]. Além disso, a crescente necessidade de competitividade e eficiência na agricultura, inerente ao capitalismo, tem contribuído, cada vez mais, para a exclusão de pequenos produtores que encontram dificuldades de diversas naturezas para se integrar. O neoliberalismo, refletido na competitividade das commodities no mercado global, resultou em pressões sobre os preços, que deterioraram a renda e as condições sociais de muitos produtores e trabalhadores do setor [12]. Segundo Mazoyer \& Roudart [10], os maiores desafios para a agricultura brasileira são: sustentar os avanços na competitividade internacional e, ao mesmo tempo, inserir os pequenos produtores no processo de desenvolvimento.

A inserção no comércio internacional apresenta desafios e oportunidades no que se refere à obtenção de ganhos. A Declaração de Roma enxerga o comércio internacional como elemento fundamental para a segurança alimentar, alegando que ele estimula o crescimento econômico, rendimento, emprego, aumenta as oportunidades de melhora no acesso aos alimentos, contribui para redução das oscilações de preços, de produção e permite que o consumo seja maior que a produção. Para isso, as políticas comerciais e internas devem ser adequadas, além de exigir infra-estrutura eficiente, assistência técnica e financeira, redução de subsídios e solidariedade de países desenvolvidos em relação aos subdesenvolvidos. O comércio internacional não deve, por si só, levar à redução da pobreza e da insegurança alimentar. Para que seja efetivo nesses objetivos deve considerar políticas complementares com estratégias diferenciadas para os mais desfavorecidos. Dessa forma, a expansão dos mercados pode, por meio do crescimento, levar à redução da pobreza e da insegurança alimentar contribuindo para $O$ desenvolvimento sócio-econômico de regiões produtoras de países subdesenvolvidos ${ }^{[13]}$.

No âmbito da Organização Mundial de Comércio, durante a conferência de Seattle, manifestações levantaram a questão das desigualdades criadas pelas rodadas anteriores de negociações e reforçaram a necessidade de conscientização quanto à responsabilidade coletiva pelos problemas enfrentados pelos países pobres [11]. Uma iniciativa importante nesse sentido é o Pacto Global (Global Compact) da Organização das Nações Unidas (ONU) que visa mobilizar as empresas para que cumpram certos requisitos com relação a direitos humanos, relações de trabalho, meio ambiente e combate à corrupção tendo em vista um mercado global mais inclusivo e igualitário. Consiste em uma iniciativa voluntária, compartilhando com o setor privado a responsabilidade de promoção do crescimento sustentável considerando os Objetivos de Desenvolvimento do Milênio [14]. Nesse âmbito, o Comércio Justo pode contribuir diretamente para a meta de erradicação da pobreza extrema e fome, na medida em que pode gerar mais empregos produtivos e trabalhos para todos.

Além disso, existe uma tendência crescente de mudanças de valores sociais refletida no comportamento dos consumidores e nos produtos consumidos. Em confronto ao modelo fordista de consumo de massas, há o surgimento de um consumidor individualista, o que possibilita a abertura de novos nichos de mercado para satisfazer tais valores sociais. Com isso, há uma tendência de aumento dos produtos ofertados, cuja adequação aos valores sociais se torna um processo de agregação de valor [15].

Um desafio importante consiste em conciliar a produção de alimentos de acordo com padrões internacionais ao respeito de culturas e tradições locais, ou seja, a liberdade de se produzir como se quer. Além disso, a produção de alimentos deve ser efetiva na geração de empregos e de rendimentos com uso de tecnologias adequadas, baratas e práticas inovadoras, que incluem o processamento e a diversificação. Isso envolve a necessidade de programas de educação e desenvolvimento dos conhecimentos técnicos, além de pesquisas para promover o aumento sustentável da produção, inovações e organização de produtores. Segundo Gordillo de Anda [16], melhorias no rendimento da pequena agricultura podem levar à ampliação do acesso a um número maior de pessoas, que, por sua vez, 
através do aumento da demanda, devem estimular a produção de pequenos produtores.

Segundo Maluf [0], a globalização pode ser usada no sentido de fortalecer as diversidades regionais, ou seja, o mesmo processo que resulta na massificação de hábitos alimentares também pode ser usado para divulgar a diversidade cultural. Entretanto, esse processo de interação entre culturas submete-se em grande parte à lógica mercantil e é apropriado pelas grandes corporações agroalimentárias. Dessa forma, os desafios para que haja uma maior inserção, geradora de emprego e renda com redução das desigualdades, são muito grandes e ainda maiores se for considerada a noção de soberania alimentar em contraposição à padronização da maneira de produzir a que foram submetidos os países como resultado da revolução verde.

Essas tendências são resultantes da configuração mundial liberal e não podem ser resolvidas unilateralmente, exigem políticas globais, concertadas entre todos os países. A estratégia deve priorizar a reconstrução do poder de compra dos países pobres, que ainda possuem grande parte de suas necessidades não satisfeitas ${ }^{[10]}$.

\section{Comércio Justo como uma estratégia de diferenciação para a agricultura brasileira}

A Economia Solidária surgiu como uma alternativa para os produtores e trabalhadores marginalizados pelo mercado, incentivando o cooperativismo, permitindo assim a adoção de progresso técnico com ação coordenada. No Brasil, teve início nos anos 70, através de iniciativas de ONG's internacionais associadas à igreja católica e às organizações de trabalhadores rurais, dando origem na década de 1980 às Redes de Economia Solidária, que prosperaram em 1990 como resposta ao desemprego [17]. A Economia Solidária compreende um grupo de atividades econômicas produção, distribuição, consumo e crédito - sendo organizada e sustentada com cooperação, auto-gestão, viabilidade econômica e solidariedade [18]. A unidade básica da economia solidária é a cooperativa regida pelos princípios legítimos estabelecidos em Rochdale ${ }^{2}$. O cooperativismo, como alternativa para inserção de pequenos produtores, possibilita melhoria nas condições de produção e comercialização, substituindo ações individuais por ações coletivas baseadas em valores

\footnotetext{
2 Adesão aberta; controle democrático; juros limitados ou fixados sobre o capital subscrito; distribuição de parte do excedente, proporcional à participação; neutralidade política e religiosa; vendas à vista; promoção da educação.
}

humanísticos como solidariedade, confiança e organização funcional de grupos. Possibilita a participação e inclusão social de pequenos negócios no processo de globalização, tornando-os mais produtivos, flexíveis e capazes de gerar produtos de melhor qualidade com maiores condições de êxito no contexto econômico mundial [19]. Além disso, as cooperativas diminuem os riscos e possibilitam maior agregação de valor para produtores rurais que não tem condições favoráveis no relacionamento com mercados concentrados [20].

Para Singer [21], os Princípios de Rochdale conduzem a uma forma de organização explicitamente socialista na medida em que o poder de decisão pertence aos sócios por igual, é livre a entrada e saída (não opera apenas a serviço dos sócios), e possui patrimônios divisíveis e indivisíveis. Segundo esse autor, o socialismo compreende uma economia organizada de tal forma que qualquer indivíduo tenha acesso a crédito para adquirir meios de produção para desenvolver a atividade que escolher. $\mathrm{O}$ produtor deve receber pela produção uma remuneração que supere seus custos e que lhes proporcione um padrão decente. A união e a ajuda mútua criam resistência à propensão da centralização do capital e promovem um sistema de trocas monetárias, no qual a moeda atua como instituição social sendo assim, menos dependente da política monetária.

Segundo Vasconcelos [22], a Economia Solidária conta com uma racionalidade específica que difere da lógica do mercado e do lucro e que leva em consideração o cooperativismo, a solidariedade, o mutualismo e a autogestão comunitária.

O Comércio Justo (Fair Trade) é reconhecido como uma das iniciativas de Economia Solidária e pode ser visto com uma alternativa ao comércio tradicional, que visa à integração de produtores com consumidores dispostos a buscar uma alternativa para a desigualdade e injustiça, recompensando cooperativas com objetivos sociais, preocupações ambientais e capacidade de melhorar as condições de trabalhadores dos países subdesenvolvidos [23]. Surgiu a partir de iniciativas humanitárias e solidárias no pós-guerra. Os debates que defendiam trade not aid durante a Conferência das Nações Unidas sobre o Comércio e o Desenvolvimento de 1968 influenciaram as organizações então existentes: SOS Wereldhandel (depois Fair Trade Organization- FTO) e OXFAM. A primeira engajou-se em campanha contra políticas protecionistas européias e a segunda na preservação da identidade cultural das populações e questões igualitárias [24]. O Comércio Justo tem o propósito de criar oportunidades para produtores que estão em desvantagem econômica ou marginalizados 
pelo sistema de comércio, corrigindo a defasagem de preços das commodities pela aproximação entre o produtor e o consumidor, além de possibilitar o estabelecimento de preços justos que não apenas cubram os custos de produção, mas que permitam a produção com justiça social e desenvolvimento [25].

A partir dos anos noventa, quatro organizações definiram as orientações estratégicas, os critérios e os princípios do comércio justo de modo a auxiliar produtores e trabalhadores marginalizados a passar de uma situação de vulnerabilidade para uma situação de maior auto-suficiência econômica, a fortalecê-los como parte de suas organizações e a buscar maior equidade no mercado internacional. A Fairtrade Labelling Organization (FLO), dividida em FLO International e FLO-Cert, é a única certificadora e auditora do selo, tem por objetivos definir os padrões de comércio justo, facilitar relações entre organizações, dar suporte técnico aos produtores e influenciar as negociações no âmbito internacional. A International Fair Trade Association (IFAT) é a organização dos produtores e tem por objetivo melhorar suas condições e integrar as organizações. A Network of European World Shops (NEWS) é a rede de lojas e tem por objetivo harmonizar os critérios do comércio justo, desenvolver meios de monitoramento, coordenar ações de sensibilização de consumidores e atores políticos. A European Fair Trade Association (EFTA) é a rede de importação, visa tornar importadores mais eficazes e eficientes, promover o comércio justo junto aos tomadores de decisões comerciais e políticas. A FINE (sigla formada pelas iniciais das quatro organizações integrantes) promove a articulação entre essas organizações, visando ao monitoramento integrado e à defesa do comércio justo no âmbito internacional. $\mathrm{O}$ Comércio Justo estabelece exigências éticas de respeito aos direitos fundamentais do trabalho definidos pela OIT, respeito às normas ambientais, desenvolvimento social, justa remuneração de produtores, relações mais igualitárias entre produtores de países subdesenvolvidos e consumidores [24].

Em 2001, a FINE estabeleceu a definição de Comércio Justo:

"O Comércio Justo é uma parceria comercial baseada em diálogo, transparência e respeito, que busca maior igualdade no comércio internacional. Ele contribui para o desenvolvimento sustentável ao oferecer melhores condiçoes comerciais e assegurar os direitos de produtores e trabalhadores marginalizados especialmente no Hemisfério Sul." [26]

Dessa forma, o Comércio Justo baseia-se em uma rede global que envolve produtores, comerciantes, distribuidores, agentes públicos, privados e consumidores com foco na construção de relações comerciais mais igualitárias. As organizações envolvidas consideram que os termos de troca nas relações comerciais entre países ricos e pobres são desiguais de modo a dificultar o desenvolvimento das populações mais desfavorecidas, ou seja, o modelo tradicional de comércio é injusto e excludente. O Comércio Justo é uma tentativa de construção de um novo modelo que permita a inclusão mais igualitária de pequenos produtores de países pobres no mercado. Além da maior inclusão, também pressupõe garantia de remuneração (preço mínimo), préfinanciamento, contratos de longo prazo, transparência, produtos de qualidade, eliminação da exploração do trabalho e produção com considerações multidimensionais.

O Comércio Justo considera o setor autônomo como fonte de emprego e renda para os desempregados pelos outros setores dentro de uma agenda de desenvolvimento do país e não como política social compensatória [22]. Os princípios e práticas do Comércio Justo são fortemente relacionados com os da Economia Solidária [18]:

1. Ética, transparência, relações co-responsáveis entre os diferentes agentes.

2. Remuneração justa e construção de relações solidárias na economia.

3. Valorização da diversidade cultural, conhecimento e imagem de comunidades tradicionais.

4. Efetiva integração entre produtores e consumidores finais, incentivo à difusão de produtos regionais no mercado local.

5. Estímulo à preservação ambiental.

Para conseguir a certificação do Comércio Justo, os pequenos produtores devem formar uma organização, administrada democraticamente pelos próprios membros, que possa contribuir para o desenvolvimento econômico e social dos membros e da comunidade. Essa organização deve seguir os requerimentos mínimos e progressivos com relação ao desenvolvimento social, econômico e ambiental [27]. O cooperativismo é uma boa alternativa para inserção de pequenos produtores, melhoria nas condições de comercialização e escoamento da produção, pois substitui ações individuais por ações coletivas baseando-se em valores humanísticos como solidariedade, confiança e organização funcional de grupos. Possibilita a participação e inclusão social de pequenos negócios no processo de globalização 
tornando-os mais produtivos, flexíveis e capazes de gerar produtos de melhor qualidade com maiores condições de êxito no contexto econômico mundial [19].

Para que o produto final receba o selo Fairtrade, é necessário que todos os elos da cadeia cumpram os critérios estabelecidos. Esse certificado, além de garantir que o produtor obedece a condições sociais, ambientais e trabalhistas mínimas, garante a distribuição mais igualitária dos recursos ao longo da cadeia produtiva e a origem de produtos, qual seja, de pequenos produtores e trabalhadores assalariados do Hemisfério Sul (120 países) que foram desfavorecidos econômica e socialmente pelas condições comerciais. São realizadas inspeções anuais para garantir a credibilidade do selo e para monitorar o impacto no desenvolvimento socioeconômico da comunidade [12].

Essa estrutura visa a:

1. Parceria e respeito entre produtores e consumidores.

2. Preço justo para assegurar desenvolvimento sustentável do ponto de vista social e do ambiental.

3. Condições de trabalho saudáveis.

4. Redução da pobreza devido ao maior acesso ao mercado.

5. Parcerias estáveis, transparentes e duradouras.

6. Garantia de salários mínimos e pagamento à vista.

7. Assistência financeira.

8. Programas de desenvolvimento da comunidade.

9. Estímulo a melhores práticas ambientais.

Os produtores são os principais beneficiários do Comércio Justo. A certificação da FLO lhes garante um preço mínimo de comércio justo, um prêmio de comércio justo e o acesso a um pré-financiamento de até $60 \%$. Os preços mínimos garantem o recebimento, pelos produtores, de valor equivalente ao custo de produção sustentável de sua mercadoria; entretanto, quando esse preço for menor que o preço de mercado, o valor mais alto se aplica. O prêmio equivale a um extra que os consumidores pagam por esses produtos, que se reverte para o desenvolvimento social e econômico coletivo da organização, principalmente de trabalhadores. O préfinanciamento tem o objetivo de garantir liquidez e dar condições para que os produtores iniciem sua atividade. O objetivo maior dessa proposta é mover os produtores e trabalhadores marginalizados de uma posição de vulnerabilidade para a auto-suficiência, fortalecendo-os como proprietários de suas organizações e permitindo que obtenham equidade no comércio internacional [12]. No curto prazo, o comércio justo visa oferecer vantagens a produtores e trabalhadores rurais, através de melhor remuneração, no longo prazo visa a influenciar as regras do comércio internacional equilibrando as relações comerciais [24].

Segundo Pérez, Rico \& Arechaga [23], os preços das principais commodities são fortemente manipulados pelas multinacionais; sendo assim, os preços pagos não retribuem o valor do trabalho revertido no produto. Por isso, o pagamento de um sobrepreço (10 a $15 \%$ do preço de mercado) é condição essencial para que haja Comércio Justo.

Van Hauwermeiren ${ }^{[28]}$ ressalta que produtos com vantagens comparativas podem apresentar dinâmica desigual entre os países, existe mobilidade internacional de capital, externalidades e alguns produtos apresentam preços instáveis. Dessa forma, os custos devem embutir danos ambientais, à saúde de trabalhadores e da população, exploração de recursos naturais e mão-deobra. O Comércio Justo é uma alternativa que incorpora objetivos de sustentabilidade no processo de liberalização econômica, impondo limites ambientais e sociais. Promove a internacionalização dos custos sociais e ambientais através da sensibilização de consumidores solidários com os produtos de países em desenvolvimento. Segundo o autor, o comércio não deve ser usado apenas visando ao crescimento econômico, mas também para promover um desenvolvimento social e ambientalmente sustentável.

Dessa forma, os preços mais altos dos produtos do Comércio Justo são fundamentais para que a produção seja sustentável. Esse é o diferencial que garante a sobrevivência desses produtores, que não têm condições de produzir com a eficiência e competitividade estabelecidas em termos globais.

Por ser uma certificação, o selo de Comércio Justo exige credibilidade e adesão, para que se sustente. Por isso, esse movimento inclui atividade de conscientização dos consumidores e do governo. A FINE trabalha na promoção do selo para que nele seja reconhecida a garantia de um sistema transparente de promoção do desenvolvimento sustentável. 


\section{Referencial teórico: Desenvolvimento como Liberdade - Amartya Sen}

$\mathrm{Na}$ visão de Amartya Sen [29] o desenvolvimento relaciona-se à expansão das liberdades, sendo que a pobreza e carência de oportunidades econômicas são fontes potenciais de privação de liberdade que estão fortemente relacionadas ao problema exposto nesse trabalho. $\mathrm{O}$ autor ressalta a participação no intercâmbio econômico, da qual são privados diversos produtores, como papel básico na vida social. O desenvolvimento é visto como um processo integrado de expansão de diferentes tipos de liberdades interligadas que influenciam-se mutuamente, ou seja, a expansão de liberdades relacionadas à esfera econômica tem influência direta e indireta sobre outras liberdades econômicas, sociais e políticas, sendo mutuamente influenciada por elas. Sendo assim, na visão desse autor a liberdade é vista como o fim e o meio para o desenvolvimento.

Nesse sentido a pobreza é vista não como a mera privação de renda, mas como a ausência de liberdade de as pessoas levarem a vida que elas escolherem, inclusive considerando a pobreza como uma dessas opções quando, por exemplo, tem-se que optar entre modernidade e tradição. Nessa visão, as políticas de combate à pobreza devem ser focadas no desenvolvimento das capacidades, com educação e participação, e assim resultar no enriquecimento da vida humana tendo como consequência a expansão da renda. A questão da fome relaciona-se à questão da pobreza de forma abrangente: o potencial para comprar comida tem que ser adquirido e a força de trabalho é a única dotação por grande parte da humanidade.

No sistema capitalista o mercado é onde se realiza o intercâmbio de mercadorias e dinheiro. Portanto, a negação da liberdade de transações é uma falha da sociedade ao privar a prosperidade com base nessas transações. Sendo assim, questões relacionadas à ética empresarial têm que ser relacionadas e a criação de oportunidades sociais deve expandir as capacidades humanas e a qualidade de vida. O conflito existente entre eficiência (liberdade dos mecanismos de mercado) e equidade (desenvolvimento como liberdade) resolve-se priorizando as questões sociais globais, o que implica na suplementação por outros mecanismos institucionais.

O auto-interesse motiva as ações, mas existem outros componentes sociais, como o senso de justiça, que também as motivam. As idéias éticas, de justiça e equidade variam entre as pessoas, mas são intrínsecas aos seres sociais, nos quais a capacidade de pensar em outras pessoas não é estranha e não precisa ser criada artificialmente. O próprio capitalismo sobrevive graças a estruturas institucionais e princípios éticos de comportamento no mercado, como a confiança, entretanto tal ética capitalista é limitada em outras questões como: desigualdades social e econômica, proteção ambiental e cooperação. Sen ${ }^{[30]}$ destaca o distanciamento entre economia e ética e considera que a produtividade da economia deve aumentar se as considerações éticas, intrínsecas ao comportamento humano, forem melhor e mais explicitamente atendidas. Tais considerações éticas podem alicerçar o bem-estar do indivíduo em bases mais amplas que o consumo individual e que levam a benefícios mais gerais para o grupo. Sendo o comportamento uma questão social, o senso de identidade ao grupo faz com que se considere os objetivos das outras pessoas e a interdependência entre esses objetivos.

\section{Segurança Alimentar e Comércio Justo.}

As populações agrícolas dos países subdesenvolvidos têm apresentado forte vulnerabilidade com relação ao acesso aos recursos que poderiam garantir-lhes Segurança Alimentar. As tendências recentes têm acentuado suas dificuldades em relação à competitividade, acesso ao mercado e, por consequência, reduzido os recursos disponíveis a elas. Além disso, se ao invés de ajuda alimentar, considerar-se a inserção no mercado como liberdade fundamental dos indivíduos, as ações voltadas a esse fim devem trazer efeitos de longo prazo melhores e mais sustentáveis.

Pode-se dizer que o Comércio Justo é bastante compatível com a abordagem do desenvolvimento como liberdade. Sua lógica de funcionamento distancia-se da lógica da maximização do auto-interesse. Ao garantir que a produção seja exclusivamente de pequenos produtores, organizados em cooperativas, impõe as condições de produção como um diferencial. Dessa forma, confronta a competitividade econômica stricto sensu, principalmente relacionada à escala, com outros valores, como a ética, solidariedade, preocupações sociais, ambientais e o desenvolvimento, como um todo. A discriminação de produtores de acordo com o tamanho da propriedade incorre em perdas em economias de escala, mas constitui-se em barreira à entrada podendo proporcionar um tipo de produção diferenciada, mais intensiva em mão-de-obra e com maiores possibilidades de dedicação aos tratos culturais. Dessa forma cabe às organizações e aos produtores escolher culturas e tratos adequados e saber explorar essas vantagens competitivas no mercado para que essa certificação atenda ao objetivo de melhorar as condições de produtores em desvantagem. 
Considerando o desenvolvimento como expansão de liberdades, pode-se argumentar, em primeira instância, que ao ampliar as possibilidades de inserção dos produtores no mercado, o Comércio Justo está lidando com uma das principais fontes de privação de liberdades: o mercado é fonte de recursos e é nele que as mercadorias, inclusive a força de trabalho, são trocadas por dinheiro, que é essencial para que se estabeleçam novas transações. Os problemas da pobreza e da fome podem, em grande parte, ser resolvidos nesse campo. Além disso, os diferentes tipos de liberdade tem interfaces comuns e uma vez que um tipo é favorecida, como a liberdade econômica, surge um efeito cascata em direção às demais liberdades. As organizações do Comércio Justo enxergam a interligação entre as liberdades e atuam no sentido de ampliá-las de forma integrada.

Conforme se cria uma especialidade, o produto agrícola deixa de participar de um mercado próximo à concorrência perfeita, ou seja, perde a característica de commodity e pode permitir aos seus produtores uma maior apropriação das margens. O Comércio Justo ao prever as relações contratuais entre produtores e intermediários e estabelecer margens mínimas para cada elo da cadeia, contribui para a redução do oportunismo e dos custos de transação. A rede de Comércio Justo busca melhorar a questão da informação, que é fator importante dos custos de transação, e confere maior poder de barganha aos seus participantes.

Devido ao fato de a unidade básica do Comércio Justo ser a organização dos produtores em cooperativas, com divisão de responsabilidades, trata-se de um problema de interdependência recíproca, em que as decisões são tomadas conjuntamente e os agentes dependem mutuamente das ações uns dos outros. A aprendizagem se retroalimenta e a potencial apropriação de margens é muito maior do que as alternativas, pois estas tendem a permanecer no segmento rural e a atuar no sentido de reverter a queda da renda dos produtores de pequena escala [31]. Esse tipo de organização per se é bastante importante para desenvolver as capacidades dos produtores nela inseridos, atuando na capacidade de organização, participação social e no desenvolvimento de capacidades humanas baseados em valores humanísticos como solidariedade, confiança e organização funcional de grupos. As ações sociais para as quais os prêmios do Comércio Justo são revertidos atuam no mesmo sentido. Essas ações são voltadas para a educação dos produtores e da comunidade em que se inserem, melhorando as capacidades humanas, ampliando a participação e a capacidade decisória. A certificação de Comércio Justo ainda estabelece requisitos progressivos co relação ao desenvolvimento dessas capacidades.

As organizações do Comércio Justo visam à redução dos custos de transação proporcionando maior transparência e harmonizando as regras do sistema como um todo, além de promover a maior participação de agentes de vários segmentos da cadeia no processo decisório. A certificação garante os atributos dos produtos mas, por outro lado, restringe a participação.

Do ponto de vista da relação com o consumidor, essa certificação visa transparecer as relações humanas, históricas e ambientais que estão escondidas em cada produto, possibilitando melhorias qualitativas nesses termos ${ }^{[32]}$. Para esses autores a questão a ser resolvida é a intensidade da relação entre coisas, em detrimento da relação entre pessoas, que encontra-se fortemente impregnada na sociedade. A possibilidade de as coisas se trocarem entre si e terem um valor inerente a elas - que determina as trocas - esconde as relações de exploração social e ambiental que estão por trás dessa mercadoria. O trabalho abstrato distorce tais relações ao permitir a comparação entre agricultores que se utilizam de modos de produção muito distintos, com custos diversos e que obtém o mesmo preço pelo produto final. A noção de Soberania Alimentar relaciona-se estreitamente com essa idéia e o sucesso da certificação de Comércio Justo nesse sentido depende da importância dos valores éticos na sociedade e de como essa certificação transmite esses valores para os consumidores. Para que se sustente, o Comércio Justo deve funcionar como uma certificação que garanta que produtos produzidos em condições especiais, menos eficientes economicamente, mas de qualidade superior, proporcionada por essa forma de produção particular que embute valores éticos, consigam se inserir no mercado competitivo como produtos pouco substituíveis e pouco imitáveis.

Apesar de o auto-interesse ser um grande motivador das ações individuais, atributos éticos não são estranhos aos seres sociais e podem trazer benefícios mais amplos, dessa forma cabe ao Comércio Justo resgatar esses valores para que possa obter sucesso. A solução para o dilema entre eficiência e equidade encontra-se na aproximação entre economia e ética e isso que tornaria possível priorizar as questões sociais globais e aumentar a produtividade da economia como um todo [30].

Dessa forma, o Comércio Justo poderia ser efetivo na inclusão de um número crescente de produtores agrícolas marginalizados, oferecendo um 
produto diferenciado, de melhor qualidade e com maior sustentabilidade econômica, social e ambiental. Esses produtores, com melhores condições de inserção no comércio internacional, devem alcançar maiores rendimentos e um maior acesso econômico à satisfação de suas necessidades básicas, inclusive à Segurança Alimentar. No longo prazo, essas iniciativas devem incentivar as regras do comércio internacional.

\section{Conclusão}

O Comércio Justo é organizado para ampliar as liberdades substantivas e sua efetividade nesse sentido depende do desenvolvimento de valores éticos que são naturais aos seres sociais. Dadas as complementariedades entre as liberdades, a liberdade de inserção no mercado e organização de grupos provoca uma reação em cadeia que resulta na ampliação de outros tipos de liberdades que se retroalimentam. Considerando a estreita correlação entre segurança alimentar e renda, uma vez que a liberdade de inserção no mercado deve favorecer incrementos na renda, espera-se uma redução substantiva na insegurança alimentar e a retroalimentação de ambas.

O Comércio Justo baseia-se na comercialização de especialidades das quais, cada vez mais, exige-se qualidade. Seu objetivo não é atuar em forma de ajuda, mas sim, buscar o diferencial de grupos de produtores e inseri-los de forma competitiva no mercado. Para isso torna-se primordial a transparência, o provimento de informações e o feedback dos participantes no sentido de implementar a organização, reduzindo assim os custos de transação e ampliando as margens. A interdependência recíproca, em que as decisões são tomadas conjuntamente e os agentes dependem mutuamente das ações uns dos outros, aumenta a complexidade das organizações de Comércio Justo, por outro lado, desenvolve a capacidade de organização, participação social e o desenvolvimento de capacidades humanas baseados em valores humanísticos como solidariedade, confiança e organização funcional de grupos. A comercialização por esse sistema tende a proporcionar maior margem que é, em grande parte apropriada pelos seus produtores, podendo levá-los a uma situação econômica melhor do que as alternativas.

Uma importante limitação refere-se à questão da discriminação dos produtores resultante da certificação. Ao mesmo tempo que essa certificação é fundamental para garantir atributos aos consumidores e sua comercialização, ela limita os produtores que podem participar dessas organizações. Os requisitos mínimos de qualidade do produto e organização muitas vezes não são alcançados pelos produtores, principalmente pelos mais necessitados. Nesse sentido a insegurança alimentar deve ser um fator limitante à inserção no mercado de produtores a ela submetidos devido à sua maior vulnerabilidade, sinalizando assim a importância de combatê-la no sentido de reduzir essa vulnerabilidade e permitir que a inserção no mercado melhore as condições de segurança alimentar.

Outras fontes de conflitos com as questões embutidas no Comércio Justo são valores fortemente impregnados na sociedade, como o auto-interesse e a reificação. O objetivo não é a supressão desses valores, mas a substituição gradual por valores éticos e por relações mais personalizadas. Essa é uma questão mais complicada, que no extremo, resultaria na criação de uma nova institucionalidade. Nesse sentido a regulação dos Estados no sentido de promover a soberania alimentar dos países poderia trazer resultados.

Enfim, o sucesso do Comércio Justo depende de uma maior aproximação entre economia e ética como forma de trazer avanços em termos de segurança e soberania alimentar e, em termos mais gerais, ampliar o alcance do desenvolvimento para a sociedade.

\section{Agradecimentos}

Agradeço ao professor Dr. Walter Belik pela leitura e pelas sugestões apresentadas.

\section{Referências Bibliográficas}

1. Léon A, Martinez R, Espíndola E, Schejtman A. Pobreza, hambre y seguridad alimentaria en Centroamérica y Panamá. Santiago: CEPAL Serie Politica Sociales 88, mai/04, 114p.

2. Buainain AM, Souza Filho HM, Silveira, JMJ. Inovação tecnológica na agricultura e a agricultura familiar. In: Lima DMA, Wilkinson J (Org.). Inovações nas Tradições da Agricultura Familiar. Brasília: CNPq, 2002, p. 47-81.

3. Wilkinson J, Lima DMA, Medeiros J. O Desenvolvimento Científico e tecnológico e a Agricultura Familiar. In: Lima DMA, Wilkinson J. (Org.). Inovação nas Tradições da Agricultura familiar. 1 ed. Brasilia: Paralelo 15, 2002, v. 1, p. 23-39

4. Wanderley MNB. Prefácio. In: Carneiro MJ, Maluf RS (org.). Para além da produção: multifuncionalidade e agricultura familiar. Rio de Janeiro: MAUAD, p.9-16, 2003.

5. Maluf RS, Menezes, F. Caderno 'Segurança Alimentar' Disponível em:

http://www.forumsocialmundial.org.br/download/tco nferencias_Maluf_Menezes 2000 por.pdf. Acesso em: 20/11/2009. 
6. Maluf RS. Segurança alimentar e nutricional com valorização da cultura alimentar. In: Miranda DS, Cornelli G. Cultura e alimentação: Saberes alimentares e sabores culturais. São Paulo: SESC, 2007. p143-150.

7. FAO. Roma, Itália: Deposito de documentos de la FAO; [updated 2009 Set 1; citado 2008 Dez 15]. Disponível em: http://www.fao.org/DOCREP/MEETING/005/Y71 06s/Y7106S07.htm\#P1382_147249

8. FAO. Roma, Itália: Food And Agriculture Organization Of The United Nations; [updated 2008 Dez 12; citado 2008 Dez 15]. Disponível em: http://www.fao.org/docrep/003/w3613e/w3613e00.h $\underline{\operatorname{tmf}}$

9. Gordillo de Anda G, Jiménez F. El nuevo eje de la Seguridad Alimentaria. Santiago: RLC-FAO, 2005.

10. Mazoyer M, Roudart L. Crise agrária e crise geral. In: História das agriculturas do mundo: Do neolítico à crise contemporânea. Cap.11, p. 433-492, 1997.

11. Stiglitz JE, Charlton A. Livre mercado para todos. Rio de Janeiro: Elsevier, 2007.

12. FairTrade. FairTrade Labelling Organisation; [updated 2009 Set 1; citado 2008 Nov 10]. Disponível em: www.fairtrade.net

13. FAO. Agricultural trade and poverty: Can trade work for the poor? Rome: FAO, 211p. 2005.

14. UNGlobalCompact. New York, NY, USA: United Nations Global Compact [updated 2009 Set 1; citado 2008 Dez 15]. Disponível em: http://www.unglobalcompact.org/

15. Green RH, Santos RR. Economia de red y reestructuracion del setor agroalimentario. Desarollo Econômico, v.32, n.126, p.199-225, jul-set/ 1992.

16. Gordillo de Anda G. Elementos para la elaboracion de planes nacionales de seguridad alimentaria en America Latina. In: Belik, W. Politicas de Seguridad Alimentaria y Nutrición en America Latina. São Paulo: Hucitec, 2004.

17. Singer P. Economia solidária: um modo de produção e distribuição. In: Singer P e Souza AR. A economia solidária no Brasil: a autogestão como resposta ao desemprego. São Paulo: Contexto, 2003, p. 11-28.

18. ICLEI. Fair Trade and Solidarity Economy in Brazil. 2006. [citado 2008 Nov 10]; 36. Disponível em: http://www.buyfair.org/fileadmin/template/projects/ buyfair/files/Fair Trade Report Brazil Final.pdf

19. Brasil. Presidência da República Casa Civil: Grupo de trabalho interministerial do cooperativismo. Proposta para implementação de plano para o desenvolvimento do cooperativismo. Brasília, fev. 2004. 159p.
20. Bialakorski Neto S. Agronegócio Cooperativo. In: Batalha, MO (Coord.) Gestão Agroindustrial. São Paulo: Atlas, 2001. 2 ed., v.1, cap.12. p.628-655.

21. Singer P. Economia solidária e socialismo. In: Ortega, A.C. e Almeida $\mathrm{F}^{\mathrm{o}}$, N. (orgs.) Desenvolvimento territorial, segurança alimentar e economia solidária. Campinas, Editora Alínea, 2007.

22. Vasconcelos TAC. A economia solidária na construção social do desenvolvimento territorial. In: Ortega, A.C. e Almeida $\mathrm{F}^{\mathrm{o}}$, N. (orgs.) Desenvolvimento territorial, segurança alimentar e economia solidária. Campinas, Editora Alínea, 2007.

23. Pérez JT, Rico PN, Arechaga AL. Para entender el comercio justo. Espanica, no.1, set-dez, p.5-23. 1999.

24. Machado MD, Paulillo LF, Lambert A. Comércio Justo internacional: A inserção da citricultura brasileira. In: Paulillo, L.F. (Coord.) Agroindústria e Citricultura no Brasil. Rio de Janeiro: E-papers, 2006. Cap. 10 p. 427462.

25. IFAT. Culemborg, Holanda: World Fair Trade Organisation; [updated 2009 Set 1; citado 2006 Nov 16] Disponível em http:/ /www.wfto.com/

26. FINE. Bruxelas, Belgica. Fair trade definition and principles: as agreed by FINE in December 2001. [updated 2009 Set 1; citado 2006 Nov 16] Disponível em: $\quad$ http://www.fairtradeadvocacy.org/documents/FAIRTRADEDEFINITIO Nnewlayout2.pdf

27. Fairtrade Labelling Organisation. Generic Fairtrade Standards for Small Farmers' Organisations. Dez. 2005.

28. Van Hauwermwiren S. El comercio justo como alternativa para avanzar hacia la sustentabilidad. Ecologia Política, p.183-190. 1995.

29. Sen A. Desenvolvimento como liberdade. São Paulo: Companhia da Letras, 2000. 409p.

30. Sen A. Sobre ética e economia. São Paulo: Companhia da Letras, 1999. 144p.

31. Saes MSM. Estratégias de diferenciação e apropriação da quase-renda na agricultura. São Paulo: Annablume, 2009. 197 p.

32. Hudson I, Hudson M. Removing the Veil? Commodity Fetishism, Fair Trade, and the Environment. Organization Environment 2003; http://oae.sagepub.com/cgi/content/abstract/16/4/4 13 Acesso em: 03/10/2008. 